\title{
Examination of the Average Chipping Rate on the Edges of Milled Granite Surfaces
}

\author{
István Gábor Gyurika, Tibor Szalay \\ Department on Manufacturing Science and Technology, Budapest University of Technology and Economics, \\ 3 Muegyetem rakpart, H-1111, Budapest, Hungary, gyurika@manuf.bme.hu, szalay@manuf.bme.hu
}

\begin{abstract}
The research described in this article was carried out for the purpose of developing a quantitative marker for defining the average edge chipping rate of milled granite surfaces and for testing and proving whether this quantitative marker can effectively be applied. Another aim of the research was to test the applicability of the developed measurement method and the precision of the body representing the volume loss caused by chipping. The surface edges of the milled specimens were digitised using a laser scanner and chipped volumes were defined on the basis of a body generated with the help of a point cloud, and then the errors of the volumes produced by the evaluation-purpose software were examined using a digital microscope. The investigations proved that the proposed measurement method is accurate and that the replacement body defined through measurements appropriately approximates the volume of chippings in the case of milled granite surfaces.
\end{abstract}

Keywords: Granite, qualification, quantitative marker, edge chippings, milling.

\section{INTRODUCTION}

$\mathrm{N}$ ATURAL STONES are generally used raw materials, both in the building industry and in manufacturing technology. In the building industry, granites and marbles are mainly used for housing elements, flagstones and kitchen counters. In manufacturing technology, mainly the tables and beds of ultra-precision machine-tools and coordinate measuring machines are made of natural stones. The manufacturing of such stones is carried out using automated machine-tools to an increasing extent with the aim to reduce manufacturing costs. In the last decade, NC machines were also applied in machining processes: numerically controlled cutting, sawing, and grinding machines and the most recently developed stone machining centres were used to this end.

The research introduced in this article was performed at a request coming from the industry. The problem to address was that the chipping rates of the edges of granite products were frequent sources of debates between the customer and the manufacturer. The root of this problem is the lack of a measuring method that provides a precise number which can objectively qualify the edges of milled granite surfaces. At present we can qualify only with national and international standards on the qualification of edge of granites. By these standards we get only two results: adequate or not adequate.

In the international literature, the edge chippings in the manufacturing of different brittle materials have been given considerable attention. Gogotsi et al. [1,2] examined edge chippings in the case of oxide and non-oxide ceramics undergoing different loads. They dropped a Rockwell indenter on different points to the edges, and then they measured the distance of the chippings from the edge. Based on the results of their research, they stated that the edge chipping examination and the evaluating algorithm developed within the scope of the study and described in their article are perfectly applicable for practical examinations. $\mathrm{Li}$ et al. [3] examined edge chippings in the inner corners of slots formed by abrasive drilling tools. The authors of the article developed a finite element model that assesses the effects of three manufacturing parameters (cutting depth, support length and pre-tightening load) on maximum normal stress and the von Mises stress in the environment of chippings. With the help of the model developed by the authors, the chipping rate of machining performed in different technological environments can be predicted and estimated. Petit et al. [4] developed a new measurement concept in the case of ceramics. The research introduced in the article is a comparative study, and its primary aim is to prepare an edge chipping examination capable of determining the hardness values of ceramics. For measuring the chippings, they used the maximum depth that was measurable on the front surface. Based on the experiments, it was concluded that the friction modulus obtained during the impact greatly affects the determination of hardness values. Yang et al. [5] examined the edge chipping process during the laser-assisted milling of siliconnitride ceramics. The research draw the conclusion that the number of chippings, their lengths and depths depend on the characteristics of the chippings, but the complete areas of the chippings and the maximum chipping depths are independent from the definition of chipping. Mohajerani et al. $[6,7]$ examined the edge chippings formed as an effect of hitting the edges of borosilicate glasses at a low speed. In these studies the chippings were generated with steel and ceramic spheres falling freely at a low speed. They measured the maximum impact force and examined the relation between the impact force and the size of the edge chipping caused by this very force. Based on the experiments, it is claimed that the beginning stages of a fracture process show a number of similarities with reference to Mohajerani et al.'s experiments and the quasistatic load. Chai et al. [8] examined the forming of chippings near the use of a sharp tool in the case of brittle solid materials, glasses and ceramics. The polished workpieces with orthogonal edges were loaded with a concentrated monotonously increasing normal load, and then the researchers examined the geometry and shape of the 
formed chippings. The important conclusion of the study is that there is a geometric similarity in the forms of the chippings irrespective of the materials concerned. On the cutting tools Scieszka [9] examined hard metals, which provide the materials of cutting tools, with respect to hardness and wear resistance. The main aim of the study was to examine hard metals' wear and edge chipping toughness and to make referent conclusions. The method can effectively be applied for organizing these material types into application technology groups in the case of both new and already existing tool materials. Direct research results on the natural stones were published by Bao et al. [10], who established a new model for estimating the force necessary for producing edge chippings with the concurrent use of a tool with a concentrated load. During the experiments a normal concentrated load was maintained at a constant distance from the edge on four different types of sandstones. Based on the examinations, researchers came to the conclusion that there is an obvious relation between the distance of the edge, the loading point and the maximum force, and based on this they established an estimation system. In their model, the researchers approximate the shapes of the chipping using quarter ellipsoids. Zhang et al. $[11,12]$ published significant results on fracture mechanisms of gabbro and marbles. The researchers made artificial edge chippings with the help of Vickers indenter, and then they investigated the surface of chippings and the geometry of edge with a confocal microscope. The results they concluded were based on the edge chipping processes and the influences of different stress. Kato et al. [13] created a standardization system by the qualification of machined products. In this system they identified the quality elements of edges by five respects. The size and number of edge chippings were part of this standardization system. Harnicarova et al. [14] expanded a new view on a deformation process caused by laser beam action and on possibilities of using the surface topography. Thanks to this procedure, it was possible to observe and to measure a development of the numerical values of the surface (profile) roughness parameter "Ra". During the research they checked the surface topography and the edge forms in various laser cut surfaces. Kuhinek et al. $[15,16]$ researched the various material parameters on the cut rock samples. In their paper they described instrumental measurement uncertainties and their influence on the result obtained from determination of rock sample uniaxial compressive strength and deformability. The analysis gives recommendation on how to improve the overall performance by using conditioning modules with better properties or by increasing the excitation voltage.

Based on the studies introduced above, a qualitative system was developed, which is able to objectively determine the average edge chipping rate in the case of a milled granite edge. This research primarily aims to examine the error of the developed quantitative marker, which is calculated on the basis of to what extent the related replacement body representing the loss of volume generated by the chipping work compares to the real chipped volume. For the research, we chose five granite types of different grain sizes with the aim to cover all granite groups appearing in the international standard. We used an Italian Prussiani NC stone machining centre and produced five sample surfaces on each stone using five different cutting speeds. After machining, we digitised the edges with a Scantech laser scanner. As the next step, we determined the volume losses generated by the chippings using the Rapid Form software. In the last step, we examined the errors of the volume loss values obtained by the Rapid Form software using a digital microscope and its software. Based on the results of the studies conducted so far, it may be claimed that the quantitative marker suggested by our study may prove appropriate for the qualification of chippings in the case of milled granite surfaces. For the assessment of the reliability of the quantitative marker and for the evaluation of the limits of the widespread use of the marker, further investigations were conducted. The results of these investigations are summarised below.

\section{MEASURING METHOD DEVELOPED TO EVALUATE THE CHIPPING RATE}

Gyurika [17] established a quantitative marker that can objectively qualify the average edge chipping rate of milled granite surfaces responding to customer needs and industrial problems. Customers may express objections related to the finished product if they think that the chippings of the edge of a stone product are bigger than expected, and in this case they may refuse to pay for the product. Actually, the limit of acceptance is at the customers' subjective discretion so the manufacturer is particularly vulnerable in this respect. The chippings may also cause further problems when, after the machining of a plane or of an island, additional rounding of the edges is still necessary as a subsequent operation. In this case, however, the definition of a maximum chipping depth is necessary instead of an average value in order to define the radius of rounding. In order to solve these problems, theoretical bases for a quantitative marker capable of objectively qualifying the edge chipping have been developed and elaborated. In line with customer demands, the qualitative system has two elements. One is the so-called 'average edge chipping rate', which defines the average size of the given chipping projected on a certain length of the edge. The other quantitative marker is the 'maximal edge chipping depth', which provides manufacturers with a strong standpoint in the case of rounding or chamfering for the purpose of defining the rounding radius or the chamfering edge length.

In the case of the average edge chipping rate, the basis of the quantitative marker is the volume loss forming on the edge of the workpiece as a result of the edge chipping generated by machining. The calculation of the total volume reduction on the examined edge (1) is as follows:

$$
\sum_{i=1}^{n} V_{i}=V_{1}+V_{2}+V_{3}+\cdots V_{n}
$$

Where:
" $\mathrm{V}_{1}, \mathrm{~V}_{2}, \mathrm{~V}_{3}, \mathrm{~V}_{\mathrm{n}}$ " are the volume reductions generated by the chippings formed on the examined edge $\left[\mathrm{mm}^{3}\right]$. 
For the purpose of generating a dimensionless quantitative marker, which is independent from the examined edge length, a proportion has to be defined in which we pair up the body that has the chipped edge and the full body without any chippings. In order to compare the average edge chipping rates of bodies of different sizes, we need a general body representing the whole volume that makes our quantitative marker independent from the product size when this number is applied. The body representing the whole volume has been defined as a quarter of a cylinder (2) (supposing that the two surface elements defining the edge of the stone are angled at $90^{\circ}$ ):

$$
V_{0}=\frac{r_{h}^{2} \pi}{4} \cdot L
$$

Where:

$$
\begin{aligned}
& \text { " } \mathrm{r}_{\mathrm{h}} \text { " is the quarter cylinder's hypothetic radius } \\
& \text { value }[\mathrm{mm}] \text { and } \\
& \text { " } \mathrm{L} \text { " is the length of the examined edge }[\mathrm{mm}]
\end{aligned}
$$

The application of quarter cylinder results in the scenario that the quantitative marker of edge chipping is independent from the original size of the stone product, and it is possible to concurrently take the length of the examined edge into consideration [18]. Experimental studies showed that the application of a hypothetic radius value of $1 \mathrm{~mm}$ resulted in acceptable chipping rates for future comparisons (Fig.1.).

The dimension-independent quantitative marker that defines the average edge chipping rate $\left(\mathrm{M}_{\mathrm{avg}}\right)$ can then be defined as the proportion of the chipped volume and the body representing the whole volume (3).

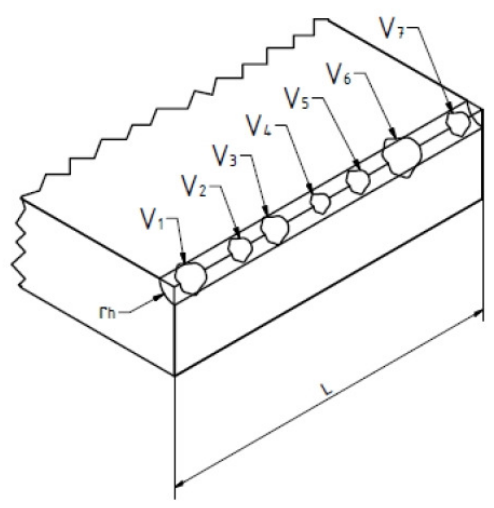

Fig.1. The structure of defining the average edge chipping rate.

$$
M_{a v g}=\left(\frac{\sum_{i=1}^{n} V_{i}}{V_{0}}\right)=4 \cdot\left(\frac{\sum_{i=1}^{n} V_{i}}{\pi \cdot L}\right)
$$

The other measure we defined in the qualitative system was the maximal edge chipping depth. It can be defined as the maximum of the two chipping depths that can be found on both surfaces forming the edge. Fig.2. explains the definition. The maximal edge chipping depth is marked ' $\mathrm{M}_{\max }$ ' henceforth (4):

$$
M_{\max }=\max \left(d_{1 A}, d_{2 A}, \cdots, d_{n A}, d_{1 B}, d_{2 B}, \cdots d_{n B}\right)
$$

Where:

- " $\mathrm{d}_{1 \mathrm{~A}}, \mathrm{~d}_{2 \mathrm{~A}}, \mathrm{~d}_{\mathrm{nA}}, \mathrm{d}_{1 \mathrm{~B}}, \mathrm{~d}_{2 \mathrm{~B}}, \mathrm{~d}_{\mathrm{nB}}$ " are the local maximal chipping values measurable on the surfaces [mm].
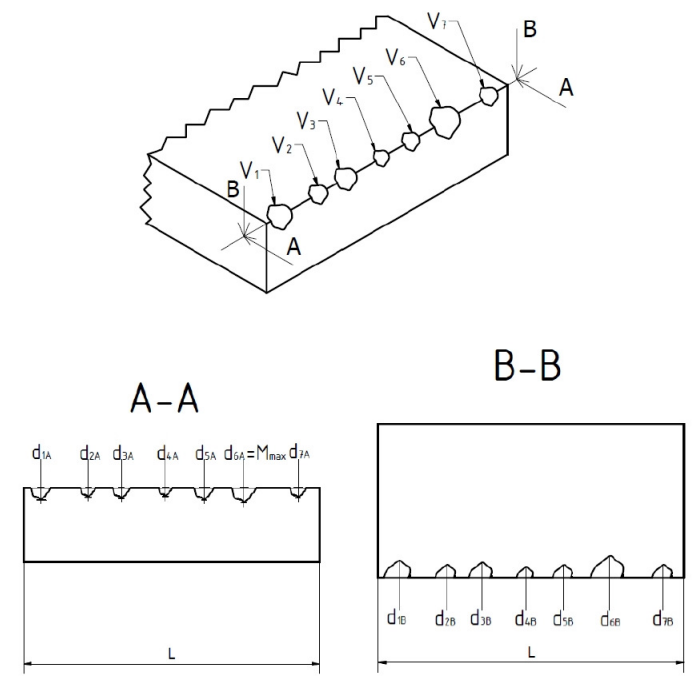

Fig.2. Definition of the maximal chipping depth.

The third aim of the research was to find a replacement body that could represent the volume losses generated by the chippings of the milled granite surface edges with high accuracy. After the assessments the authors got a relatively small error using a complex body that consisted of two same-volume quarter cones with elliptic bases (Fig.3.). Three parameters have to be used for defining the body. The height of the cones is equal with the distance between the starting and ending points of the chipping, and the lengths of the two axes of the ellipse that are the common bases of the cones are equal to the maximum depths of chippings measured on the two surfaces defining the edge.

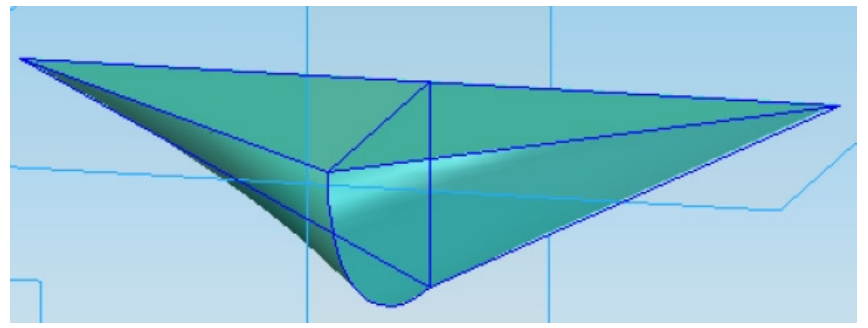

Fig. 3. Replacement body (source: [18]).

The volume losses generated by the edge chippings of each sample surface were averaged, and then the errors of the volume losses were calculated as the difference of the real volume losses and the replacement body. Based on the result of this evaluation, the conclusion was that the differences were always within $\mathrm{a} \pm 3 \%$ margin. This study 
also reveals how extensive further examinations have to be in order to prove that the application of this replacement body may be used in the case of every granite type found in the world. In this paper, the authors introduced further examination processes to achieve this aim.

\section{THE EXAMINATION OF THE APPLICABILITY OF THE REPLACEMENT BODY DEFINING THE AVERAGE EDGE CHIPPING RATE OF MILLED GRANITE SURFACES}

The broad-spectrum examination fully covers all granite types classified based on their average grain sizes for this reason, for the examinations, we chose a stone type from each group and with the help of these types we performed the relevant milling, scanning and evaluating processes. After the broad-spectrum examination had been completed, the aim during the verification process was to define the accuracy with which the Rapid Prototyping software, which calculates the chipped volumes from the scanned point cloud, defines the length and the maximum chipping depths measurable on the two surfaces against the actual values.

\subsection{Granite types selected for examination}

Based on their average grain sizes, the standard classification of natural stones defines five different classes (Table 1.).

Table 1. Classification of natural stones based on the average sizes of stone components.

\begin{tabular}{|c|c|}
\hline $\begin{array}{c}\text { Average grain sizes of the } \\
\text { stone }\end{array}$ & Name \\
\hline $\mathrm{d}>10 \mathrm{~mm}$ & large grain-size group \\
\hline $5 \mathrm{~mm} \leq \mathrm{d} \leq 10 \mathrm{~mm}$ & coarse grain-size group \\
\hline $1 \mathrm{~mm} \leq \mathrm{d} \leq 5 \mathrm{~mm}$ & middle grain-size group \\
\hline $\begin{array}{c}\mathrm{d}<1 \mathrm{~mm} \text { (the grains are } \\
\text { separable by the naked eye }\end{array}$ & small grain-size group \\
\hline $\begin{array}{l}\mathrm{d}<1 \mathrm{~mm} \text { (the grains are not } \\
\text { separable by the naked eye) }\end{array}$ & fine grain-size group \\
\hline
\end{tabular}

For the chipping examinations, we chose deep magmatic stones in which the silicate-containing rock components that tend to be chipped show significant grain size differences. Petrographic examinations were performed on slim grindings - produced from the different stone types - using a so-called petrographic microscope through twice polarized light.

Granite No. 1 is a deep magmatic stone from Italy. The structure of the grey-coloured, pink-shaded, middle-grain, crystal-grain-structured magmatic deep stone is compact. Its typical stone components are quartz and potash feldspar. Along with the main stone components, plagioclases and the so-called coloured minerals (amphibole, biotite) are also found in the stone structure. The gnarled, off-white isometric quartzes have $1-4 \mathrm{~mm}$ grain sizes. The pink orthoclases with grain sizes of $5-7 \mathrm{~mm}$ appear in intergranular bonds. Plagioclases and coloured minerals appearing along with potash feldspars are fine-grained, tabularly developed, and their grain sizes are under $1 \mathrm{~mm}$. Granite No. 1 is a representative of this class with middlesized grains.
Granite No. 2 is from Brazil, it is the Giallo Farfalla type of stone by its commercial name (Fig.4.). Giallo Farfalla is a yellowish brown-coloured, grey-shaded, crystal-structured deep magmatic stone; it is a compact granite type. It is a large-grained granite with slightly directed stone components. Its typical stone components are large-sized gnarled off-white quartz and potash feldspar. The grain sizes of the quartzes are between 1 and $10 \mathrm{~mm}$. The pink-coloured orthoclases are the other main stone components: they are twin-structured and tabularly developed, their grain sizes reach the size of $15 \mathrm{~mm}$. Along with potash feldspars, finegrained, tabularly developed plagioclases are also found in this stone, whose grain sizes are under $1 \mathrm{~mm}$. There are further coloured components in the structure of the stone. The porosity of the stone is intergranular, its value is under 5 volume percent. Granite No. 2 belongs to the large grainsize group, according to the standard.

Granite No. 3, whose commercial name is G684, comes from China, it is a greyish-coloured, dark-shaded, crystalgrained structured deep magmatic stone; it is compact gabbro. Its typical stone-component minerals are scattered, tabularly arranged 1-3 mm grain-sized plagioclase and pyroxene, which is a fine-grained and tabularly developed mineral in the sizes of $1-3 \mathrm{~mm}$. Olivine and chlorite are also found in it and these provide the coloured stone components; their sizes are under a millimetre. The porosity of the stone is intergranular, the referent rate is under 2 volume percent. This granite type represents the small grainsize group in our research.

Granite No. 4 is light grey with a pinkish shade; it is a magmatic deep stone with a crystal-grained structure. The structure of the stone is compact. Its typical stone components are quartz and potash feldspar. The off-white, isometric quartzes are scattered and vary between grain sizes of 1-5 mm. The pink coloured orthoclases, which tend to split, have twin structures. Their grain sizes vary between 6-8 mm. Plagioclases appearing along with potash feldspars are fine grained, tabularly developed and gnarled. Some coloured stone components (biotite mica) surface in the structure of this stone. The grain sizes are under $1 \mathrm{~mm}$. This stone type represents the coarse-grained granite group.

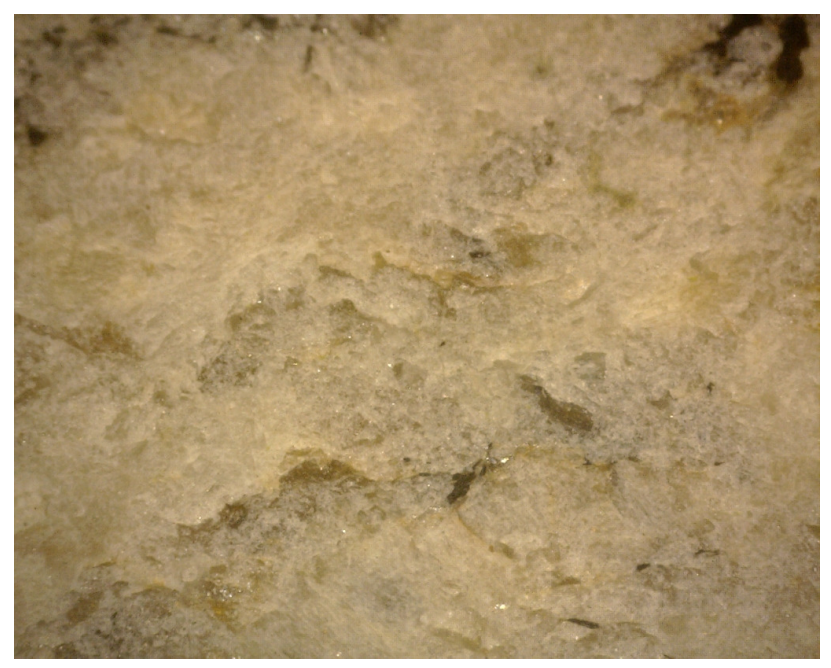

Fig.4. Giallo Farfalla granite. 
Granite No. 5 is a grey-coloured, crystal-grain-structured magmatic deep stone. Its petrographic name is gabbro. The stone is compact and has a homogeneous structure. Its typical stone components are plagioclase and pyroxene. The grain sizes of the plagioclases, which are scattered, have a dark colour, are broad and columnly developed, and vary between 1-2 mm. Pyroxenes appearing along with plagioclases are fine grained, tabularly developed and their grain sizes are between 1 and $3 \mathrm{~mm}$. Some coloured stone components, olivines and chlorites appear in the structure of the stone. The grain size of components is under $0.1 \mathrm{~mm}$. The size of the intergranular pores is under $0.1 \mathrm{~mm}$. Granite No. 5 belongs to the group of fine-grained stones.

\subsection{Examination process}

The examination process developed for the research consists of three phases (Fig.5.). The data stream between these three stages was coordinated by a database stored and handled on a personal computer, which stored the parameters of the machining environment, the scanned edges, the evaluated edge chippings, the digitised pictures and the evaluations of the additional verification.

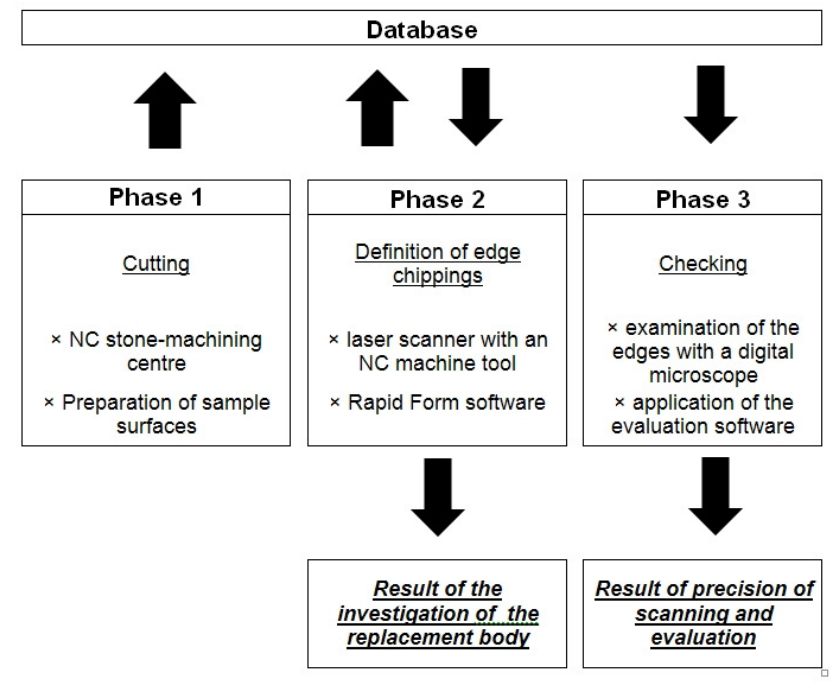

Fig.5. The applied examination process.

The first phase was the forming of the surfaces necessary for the examinations. The milling processes were performed using a Prussiani Golden Plus machine-tool, which was developed specifically for stone drilling and milling (Fig.6.). We produced five sample surfaces for each granite type. The width of the sample surfaces was $45 \mathrm{~mm}$. We applied five different cutting speeds $(200 \mathrm{~m} / \mathrm{min}, 500 \mathrm{~m} / \mathrm{min}, 800 \mathrm{~m} / \mathrm{min}$, $1100 \mathrm{~m} / \mathrm{min}, 1400 \mathrm{~m} / \mathrm{min}$ ) in the case of each stone. The depth of cut was $1 \mathrm{~mm}$ through the whole process. The machining was carried out using up-cutting.

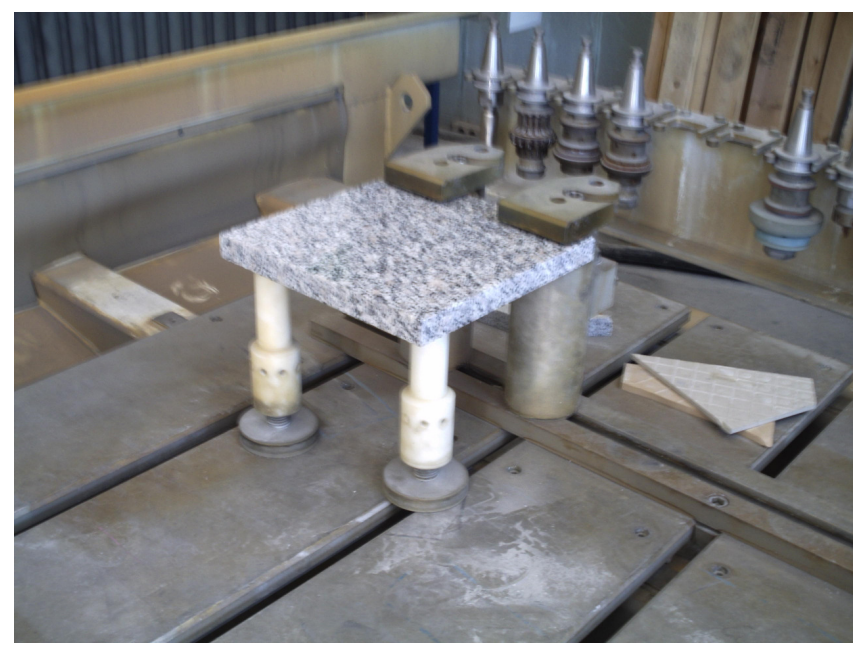

Fig.6. Fixing the granite block in the NC machine-tool.

In the second phase, the exit edges of the milled granite sample surfaces were digitised. For the digitisation, a Scantech type laser scanner was used, which was fixed in the spindle of an NC machining centre (Fig.7.). While the linear tool moved, the personal computer connected to the NC machine-tool recorded peak point coordinates in both axis directions: these points were always $0.05 \mathrm{~mm}$ away from each other.

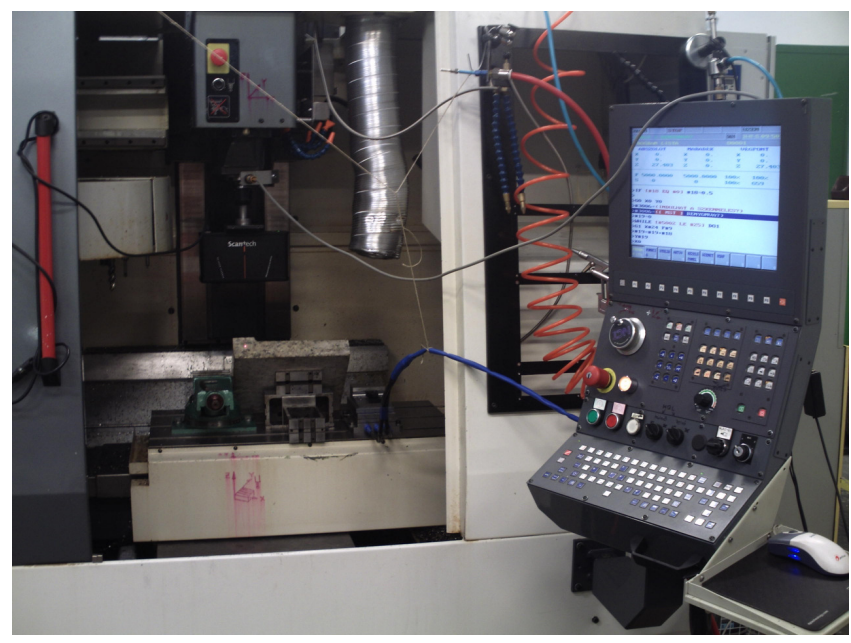

Fig.7. Laser scanner fixed in the spindle.

After this, the digitised point clouds were transformed into a format evaluable with the software called Rapid Form, which is applied in the field of rapid prototyping. First, we fitted a triangle net on these point clouds (Fig.8.). During the fitting process, the software matched the recorded peak point coordinates with triangles of $0.1 \mathrm{~mm}$ peak point distances. After this, we identified the edge chippings with the naked eye. After the identification, we separated the edges from each other and stored them in separate files (Fig.9.). 


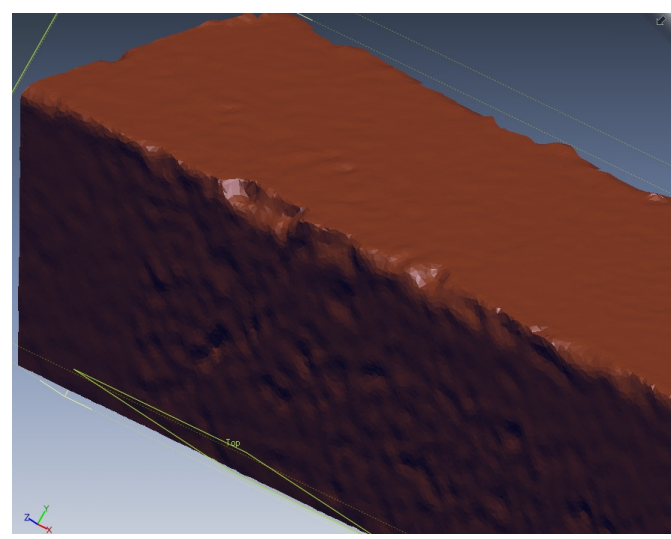

Fig.8. Digitised picture of the second sample surface of the fourth stone.

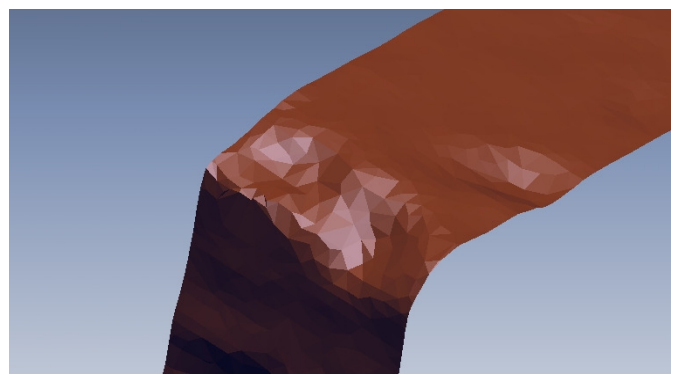

Fig.9. The third chipping of the second sample surface of stone No. 4 .

The next step was to define the volumes of the chippings. Initially, we identified the starting and ending points of each chipping in the Rapid Form software, and then we produced the body that represented the volume loss generated by the chipping. Rapid Form calculated the volume of the chipping using inner algorithms based on the body's features.

In the evaluation of the edge chipping in the scope of the whole process, the next step was the collection of data necessary for defining the replacement body (Fig.10.). For the examined replacement body's calculation, the distance between the starting and the ending points of the chipping (this gives the height of the complex cone body) and the maximum chipping depths measurable on the two surfaces forming the edge (these two parameters define the two diameters of the ellipse basis of the cone body) were required. When defining the maximum chipping depth, the examinations were performed $0.05 \mathrm{~mm}$ away from the body generated by Rapid Form. This was necessary because the scanner recorded the edge points with $0.05 \mathrm{~mm}$ intervals so we did not take the geometric changes within these intervals into account. Obviously, for verifying our hypothesis, we verified the accuracy of our application in the third phase.

In the third phase, the examinations of the accuracy and errors of the tools used for the digitisation of the edges and for the evaluation of the edge chippings were carried out. This phase is an unavoidable and important part of our research because the limits and margins of error of the replacement body's application can only be defined in a precise manner when the collective error values of the methods and measurements applied by the evaluation are exactly known.

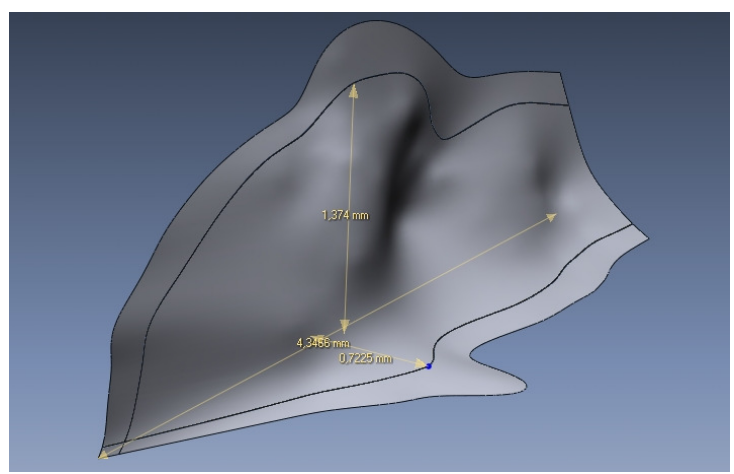

Fig.10. Body representing volume loss generated by an edge chipping.

During the verification phase, we first photographed those surfaces that form the edge of the granite products with the help of a digital microscope making sure that the edge would also appear in the pictures. We applied a magnifying value of 55 for digitising and this way we could record edge intervals of $5 \mathrm{~mm}$ in the case of each picture. We carried out the digitisation process on both surfaces that form the edge in the case of every exit edge so that we could precisely determine the distance between the starting and the ending points of the chippings and the maximum chipping depths measurable on the surfaces (Fig.11.). In the last step of the verification phase, we compared the volumes of the replacement bodies obtained during the second phase with the volumes of the complex cone bodies calculated from the parameters measured on the digitised edges.

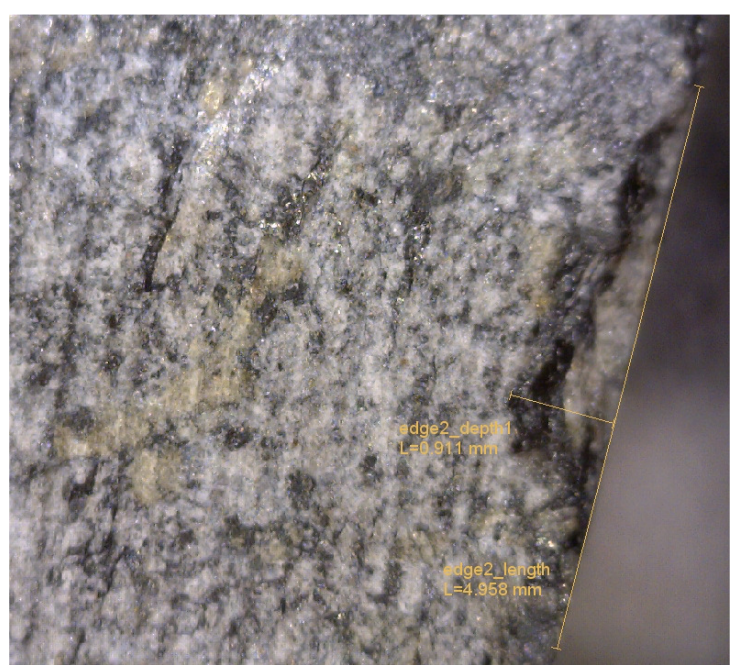

Fig.11. Edge chipping photographed and evaluated with a digitised microscope.

After having described and discussed the examination process, below we turn to the discussion of the results of the measurements.

\section{RESULTS OF THE MEASUREMENTS}

In the scope of the research introduced in this article we examined a total of 223 chippings on 25 sample surfaces of 5 types of granite. In the case of all chippings we defined the volume loss generated by edge chipping with the help of the 
Rapid Form software and with the application of the replacement body. We performed verification-purpose examinations for each edge chipping using the digital microscope and the evaluating software of the device.

Table 2. summarizes the differences between the chipped volumes calculated by Rapid Form and considered realistic and the replacement body's volumes measured on the basis of the typical parameters of the chippings in the case of all sample surfaces. In all cases, we examined the whole lengths of $45 \mathrm{~mm}$, and the measurement results below show the average of chipping volumes associated with the examined length.

Table 2. clearly shows that the following is true in the case of all applied cutting speeds: the chipped volumes' error projected on a length of $45 \mathrm{~mm}$ calculated with the application of the replacement body is within $\pm 3 \%$ compared to the average of volume values calculated using Rapid Form. This result means that in the case of the applied machining and measuring methods the complex cone body developed for replacement during previous researches can be effectively applied within a $3 \%$ range of accuracy ratio.

Table 2. Values and rates of real average chipped volumes measured on the sample surfaces and average chipped volumes calculated using the replacement body.

\begin{tabular}{|c|c|c|c|}
\hline \multicolumn{4}{|c|}{$\begin{array}{c}\text { Results concerning the investigation of sunstitution with quater-tapered } \\
\text { shell }\end{array}$} \\
\hline $\begin{array}{c}\text { Name of the sample } \\
\text { surface }\end{array}$ & $\begin{array}{l}\text { Average volume of } \\
\text { the edge } \\
\text { chippings [mm³ }\end{array}$ & $\begin{array}{l}\text { Average volume of } \\
\text { substituting }\left[\mathrm{mm}^{3}\right]\end{array}$ & $\begin{array}{c}\text { Ratio of theoretical } \\
\text { and concrete } \\
\text { volumes }\end{array}$ \\
\hline Granite 1-Surface 1 & 0.5941 & 0.6033 & $101.53 \%$ \\
\hline Granite 1-Surface 2 & 0.5756 & 0.5762 & $100.10 \%$ \\
\hline Granite 1-Surface 3 & 0.2806 & 0.2743 & $97.77 \%$ \\
\hline Granite 1-Surface 4 & 0.4066 & 0.4021 & $98.88 \%$ \\
\hline Granite 1-Surface 5 & 0.5199 & 0.5055 & $97.22 \%$ \\
\hline Granite 2-Surface 1 & 1.0588 & 1.0896 & $102.91 \%$ \\
\hline Granite 2-Surface 2 & 0.9975 & 0.9777 & $98.01 \%$ \\
\hline Granite 2 - Surface 3 & 1.3604 & 1.3233 & $97.28 \%$ \\
\hline Granite 2 - Surface 4 & 0.7706 & 0.7767 & $100.79 \%$ \\
\hline Granite 2-Surface 5 & 0.5865 & 0.5691 & $97.03 \%$ \\
\hline Granite 3-Surface 1 & 0.2576 & 0.2646 & $102.72 \%$ \\
\hline Granite 3-Surface 2 & 0.3866 & 0.3967 & $102.63 \%$ \\
\hline Granite 3-Surface 3 & 0.4694 & 0.4737 & $100.91 \%$ \\
\hline Granite 3 - Surface 4 & 0.1499 & 0.1456 & $97.10 \%$ \\
\hline Granite 3 - Surface 5 & 0.1353 & 0.1319 & $97.53 \%$ \\
\hline Granite 4-Surface 1 & 0.6942 & 0.6737 & $97.05 \%$ \\
\hline Granite 4-Surface 2 & 0.4608 & 0.4700 & $101.99 \%$ \\
\hline Granite 4 - Surface 3 & 0.3810 & 0.3720 & $97.64 \%$ \\
\hline Granite 4 - Surface 4 & 0.3674 & 0.3678 & $100.11 \%$ \\
\hline Granite 4 - Surface 5 & 0.1769 & 0.1820 & $102.91 \%$ \\
\hline Granite 5-Surface 1 & 0.1509 & 0.1471 & $97.43 \%$ \\
\hline Granite 5 - Surface 2 & 0.1677 & 0.1654 & $98.65 \%$ \\
\hline Granite 5 - Surface 3 & 0.0769 & 0.0776 & $100.93 \%$ \\
\hline Granite 5 - Surface 4 & 0.1186 & 0.1195 & $100.75 \%$ \\
\hline Granite 5 - Surface 5 & 0.0634 & 0.0615 & $97.12 \%$ \\
\hline
\end{tabular}

In Table 2. the cutting speeds are the following:

- Surface $1=200 \mathrm{~m} / \mathrm{min}$

- Surface $2=500 \mathrm{~m} / \mathrm{min}$

- Surface $3=800 \mathrm{~m} / \mathrm{min}$

- Surface $4=1100 \mathrm{~m} / \mathrm{min}$

- Surface $5=1400 \mathrm{~m} / \mathrm{min}$

In the verification phase we used a total of 223 pieces of data during the statistical examinations. The basic details of the statistical calculations were the percentages of the volumes calculated - using the replacement body - and the parameters measured on the edge chipping shown by the Rapid Form software, which were compared to the volumes defined in the verification phase with the help of the digital microscope. Through the examinations, we intended to check the error at which the volume losses, calculated from the edge chipping digitised with the laser scanner and the rapid prototyping software, approximate those volumes that are measured by the microscope and can be considered real. In both phases we measured the distances between the starting and ending points of the chippings and the maximum depths that are found on the two edge-defining surfaces. Based on the application of the replacement body defined during former researches and relying on the three above details, we could define the volume loss generated by the given chipping both in the case of the examination using the Rapid Form software and the examination using the digital microscope.

Using the Minitab 16 software, statistical calculations were completed based on the 223 pieces of data. As a result of the calculations, it is claimed that the estimation produces the data in a confidence interval of $1.74 \%$ with $90 \%$ probability. As the interval is narrow enough, we can state that the method exhibits high accuracy in terms of the compared details. In Fig.12., it can be seen that examination results display a normal distribution, with an expected value of $98.86 \%$ and a deviation of $15.81 \%$. Based on these values, we can say that the chipped volume values received from Rapid Form slightly underestimate the values measured using the microscope. Furthermore, the statistical results were put under the Ryan-Joiner fitting test. As a result of this test, it may be stated that the statistical population examined by us follows a normal distribution.

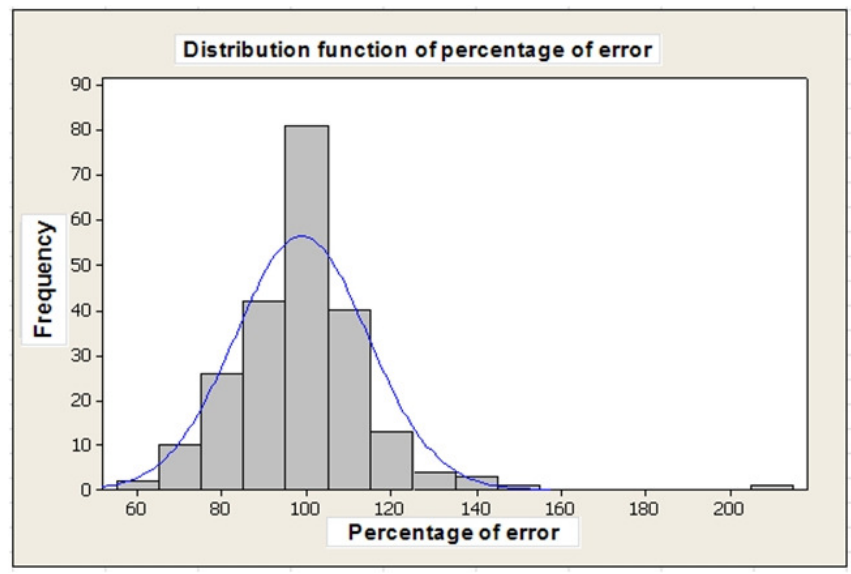

Fig.12. The distribution function of error percentages.

\section{CONCLUSIONS}

When evaluating the measured data, it was established that the error of the average of chipped volumes, projected at a measuring length of $45 \mathrm{~mm}$ and calculated applying the replacement body, was within $\pm 3 \%$ in the case of all granite types and their sample surfaces compared to the average of volume values calculated by the Rapid Form software. Based on this result, it is claimed that the replacement body can effectively be applied within the given margin of error in the case of all granite types as a body representing the edges of milled granite surfaces. The statistical analysis of the verification examination also revealed convincing results. Although the volumes of the 
replacement bodies calculated on the basis of the parameters received from Rapid Form slightly underestimate the figures measured and calculated with the help of the digital microscope, the narrow limits of the confidence interval and the slight deviation rate both show that the results received from Rapid Form can effectively be used for theoretical research.

During the next phase of our research we will investigate the efficiency of the quantitative markers and the replacement body on other brittle materials, for example on ceramics and composites.

\section{ACKNOWLEDGEMENT}

The authors acknowledge support from Woldem Kft. and István Gyurós for this research. This work is connected to the scientific program of the "Development of qualityoriented and harmonized $\mathrm{R}+\mathrm{D}+\mathrm{I}$ strategy and functional model at BME" project, supported by the New Széchenyi Plan (Project ID: TÁMOP-4.2.1/B-09/1/KMR-2010-0002).

\section{REFERENCES}

[1] Gogotsi, G., Mudrik, S., Galenko, V. (2007). Evaluation of fracture resistance of ceramics: Edge fracture tests. Journal of Ceramics International, 33, 315-320.

[2] Gogotsi, G. (2014). Classification of ceramics and glass (edge chipping and fracture toughness). Journal of Ceramics International, 40, 5591-5596.

[3] Li, Z.C., Cai, L.W., Pei, Z.J. (2006) Treadwell C. Edge-chipping reduction in rotary ultrasonic machining of ceramics: Finite element analysis and experimental verification. International Journal of Machine Tools \& Manufacture, 46, 1469-1477.

[4] Petit, F., Vandeneede, V., Cambier, F. (2009). Ceramic toughness assessment through edge chipping measurements - Influence of interfacial friction. Journal of the European Ceramic Society, 29, $2135-$ 2141.

[5] Yang, B., Shen, X., Lei, S. (2009). Mechanisms of edge chipping in laser-assisted milling of silicon nitride ceramics. International Journal of Machine Tools \& Manufacture, 49, 344-350.

[6] Mohajerani, A., Spelt, J.K. (2011) Edge chipping of borosilicate glass by low velocity impact of spherical indenters. Mechanics of Materials, 43, 671-683.

[7] Mohajerani, A., Spelt, J.K. (2010) Edge chipping of borosilicate glass by blunt indentation. Mechanics of Materials, 42, 1064-1080.
[8] Chai, H., Lawn, B.R. (2007). A universal relation for edge chipping from sharp contacts in brittle materials: A simple means of toughness evaluation. Acta Materialia, 55, 2555-2561.

[9] Scieszka, S.F. (2005). Edge failure as a means of concurrently estimating the abrasion and edge fracture resistance of hard-metals. Tribology International, 38, 834-842.

[10] Bao, R.H., Zhang, L.C., Yao, Q.Y., Lunn, J. (2011). Estimating the peak indentation force of the edge chipping of rocks using single point-attack pick. Rock Mechanics and Rock Engineering, 339-347.

[11] Zhang, Z.X., Kou, S.Q., Yu, J., Yu, Y., Jiang, L.G., Lindqvist, P.A. (1999). Effects of loading rate on rock fracture. International Jorunal of Rock Mechanics and Mining Sciences, 36, 597-611.

[12] Zhang, Z.X., Kou, S.Q., Jiang, L.G., Lindqvist, P.A. (2000). Effects of loading rate on rock fracture: Fracture characteristics and energy partitioning. International Journal of Rock Mechanics and Mining Sciences, 37, 745-762.

[13] Kato, Y., Ohmri, K., Hatano, E., Takazawa, K. (2007). The standartization of edge quality of the precise machinings products. Advanced Materials Research, 24-25, 83-90.

[14] Harnicarova, M., Valicek, J., Kusnerova, M., Grznárik, R., Petru, J., Cepova, L. (2012). A new method for the prediction of laser cut surface topography. Measurement Science Review, 12, 195-204.

[15] Kuhinek, D., Zoric, I., Hrzenjak, P. (2011). Development of virtual instrument for uniaxial compression testing of rock samples. Measurement Science Review, 11, 99-103.

[16] Kuhinek, D., Zoric, I., Hrzenjak, P. (2011). Measurement uncertainly in testing of uniaxial compressive strength and deformability of rock samples. Measurement Science Review, 11, 112-117.

[17] Gyurika, I.G. (2013). Experimental protocols to define quality metrics for milled edges in granite. In International Conference on Innovative Technologies (IN-TECH 2013), September 10-12, 2013. Faculty of Engineering University of Rijeka, 57-60.

[18] Gálos, M., Gyurika, I.G. (2014). Quality measuring numbers of milled edges of granite surfaces. Periodica Polytechnica Civil Engineering, 58, 121-129.

Received September 4, 2014. Accepted January 24, 2015. 